\title{
The Relation of Body Mass Index and Duration of Anesthesia with Conscious Recovery Time in Children with General Anesthesia in Regional General Hospital Central Java Kebumen
}

\section{Hubungan Indeks Massa Tubuh Dan Lama Anestesi Dengan Waktu Pulih Sadar Pada Anak Dengan General Anestesi Di Rumah Sakit Umum Daerah Kebumen Jawa Tengah}

Yustiana Olfah ${ }^{1}$, Reza Andisa ${ }^{2}$, Sugeng Jitowiyono ${ }^{1}$

\section{Abstract}

The calculation of body mass index and duration of anesthesia is the first step of a series of actions performed anesthesia on pediatric patients who planned to undergo anesthesia . The calculation of body mass index and duration of anesthesia determine the smoothness of anesthesia, and the patient's recovery period after general anesthesia. The study is to determine the relationship of body mass index and duration of anesthesia with conscious recovery time after general anesthesia in children using observational analytic cross sectional survey approach. The site of research is in recovery room of The Central Surgery Installation RSUD Kebumen Central Java with as many as 44 research sample consists of body mass index and duration of anesthesia, with postoperative assessment instruments Steward score. The result is patients with conscious recovery time after general anesthesia slowly, over 30 minutes is a patient with a body mass index is not ideal that 13 people ( $68.42 \%$ ) of the total sample whereas patients who recovered quickly in less than or equal to 30 minutes as many as 17 people ( $72 \%$ ) with an ideal tubu mass index of the total sample. From the statistical test Chi-square computer program values obtained value, the probability asymp. Sig . ( 2 - sided ) : 0,008 which means there is a relationship of body mass index of anesthesia with the patient recovery time, and patients recover with time after general anesthesia consciously slowly, over 30 minutes is a patient with a long lebi anesthesia time of 1 hour 12 people ( $75 \%$ ) of the total sample whereas patients who recovered quickly in less than or equal to 30 minutes of 20 people $(71.43 \%)$ with a time of anesthesia faster than the total sample. From the statistical test Chi-square computer program values obtained value, the probability

Afiliasi Penulis

1 | Jurusan Keperawatan Poltekkes Kemenkes Yogyakarta

2 | RSI ST Khadijah Palembang

Korespondensi kepada

Y. Olfah

yustianajogja@gmail.com asymp . Sig . ( 2 - sided): 0,003 which means there is a long-standing relationship with the anesthesia recovery time of patients, so there is a relationship of body mass index and duration of anesthesia with conscious recovery time

Keywords: body mass index, duration of anesthesia, recovery time conscious 


\section{Intisari}

Perhitungan indeks massa tubuh dan lama anestesi adalah langkah awal dari rangkaian tindakan anestesi yang dilakukan terhadap pasien anak yang direncanakan untuk menjalani tindakan anestesi. Perhitungan indeks massa tubuh dan lama anestesi menentukan dalam kelancaran tindakan anestesi, dan masa pemulihan pasien pasca general anestesi. Penelitian ini bertujuan untuk mengetahui hubungan indeks massa tubuh dan lama anestesi dengan waktu pulih sadar pada anak pasca general anestesi menggunakan metode observasional analitik dengan pendekatan survey cross sectional. Tempat penelitian di Instalasi Bedah sentral ruang pemulihan RSUD Kebumen Jawa Tengah, dengan sample penelitian sebanyak 44 orang terbagi atas indeks massa tubuh dan lama anestesi, dengan instrumen penilaian pasca bedah Steward score. Hasil penelitian didapatkan pasien dengan waktu pulih sadar pasca general anestesi lambat, lebih dari 30 menit adalah pasien dengan indeks massa tubuh tidak ideal yaitu 13 orang $(68,42 \%)$ dari total sampel sedangkan pasien yang pulih cepat dalam waktu kurang atau sama dengan 30 menit sebanyak 17 orang (72\%) dengan indeks massa tubu ideal dari total sampel. Dari uji statistik dengan program Chi square komputer didapatkan nilai value, dengan probabilitas asymp. Sig. (2-sided) : 0,008 yang berarti terdapat hubungan indeks massa tubuh anestesi dengan waktu pulih pasien, dan pasien dengan waktu pulih sadar pasca general anestesi lambat, lebih dari 30 menit adalah pasien dengan waktu anestesi lama lebi dari 1 jam 12 orang (75\%) dari total sampel sedangkan pasien yang pulih cepat dalam waktu kurang atau sama dengan 30 menit sebanyak 20 orang $(71,43 \%)$ dengan waktu anestesi cepat dari total sampel. Dari uji statistik dengan program Chi square komputer didapatkan nilai value, dengan probabilitas asymp. Sig. (2-sided) : 0,003 yang berarti terdapat hubungan lama anestesi dengan waktu pulih pasien, sehingga dapat disimpulkan ada hubungan indeks massa tubuh dan lama anestesi dengan waktu pulih sadar.

Kata kunci: Indeks massa tubuh, lama anestesi, waktu pulih sadar

\section{Pendahuluan}

Pembedahan merupakan tindakan pengobatan yang menggunakan teknik invasif dengan membuka atau menampilkan bagian tubuh yang akan ditangani melalui sayatan yang diakhiri dengan penutupan dan penjahitan luka ${ }^{5}$. Setiap tindakan pembedahan tidak bisa dipisahkan dengan tindakan pembiusan/anestesi. Secara garis besar anestesi dibagi menjadi tiga, general anestesi, regional anestesi dan lokal anestesi. Anestesi umum atau General anestesi (GA) adalah hilangnya rasa sakit secara sentral disertai hilangnya kesadaran (revesibel). Tindakan GA terdapat beberapa teknik yang dapat dilakukan adalah: GA dengan teknik intravena anestesi (TIVA); dan GA dengan inhalasi yaitu dengan face mask (sungkup muka) dan dengan teknik intubasi yaitu pemasangan endotracheal tube (ET); atau gabungan keduanya inhalasi dan intravena.
Pembedahan dilakukan dengan beberapa alasan seperti diagnostik (biopsi, laparatomi eksplorasi), kuratif (eksisi massa tumor, pengangkatan Apendiks yang mengalami inflamasi), refraktif (memperbaiki luka multiplek), rekonstruksi dan paliatif6. Tatalaksana anestesi dan reanimasi terdiri dari evaluasi praanestesi dan reanimasi, persiapan praanestesi dan reanimasi, pilihan anestesi dan reanimasi, standar pemantauan dasar intraoperatif serta pengelolaan pasca operatif ${ }^{7}$.

Pemulihan dari anestesi umum adalah waktu yang penuh dengan stress fisiologi bagi banyak pasien. Pemulihan kesadaran pasien pasca general anestesi sebaiknya secara pelan-pelan dalam lingkungan yang terkontrol di ruang perawatan pasca anestesi (Recovery Room atau Post Anestesi Care Unit) dengan tujuan memulihkan kesadaran pasien semaksimal mungkin tanpa komplikasi serta mempertahankan hemodinamik, kebutuhan oksigen dan membantu proses penyembuhan. 
Sering dijumpai pada masa pulih sadar ini pasien mengalami berbagai masalah, seperti adanya kejadian sumbatan jalan nafas, menggigil, agitasi, mual muntah, dan hipotermia ${ }^{6}$. Masalah pulih sadar pasca tindakan anestesi umum tidak hanya dinilai pasien telah sadar, tetapi diperlukan waktu sampai efek obat anestesi berkurang atau hilang. Oleh karena itu tenaga anestesi, khususnya perawat anestesi di tuntut untuk memahami faktor-faktor yang mempengaruhi waktu pulih sadar pasien pasca tindakan anestesi umum, efek obat anestesi (premedikasi dan induksi), usia, berat badan (indek massa tubuh), jenis operasi, lama anestesi, status fisik (ASA) dan gangguan asam basa / elektrolit? ${ }^{7}$.

Jumlah data pasien kamar operasi di RSUD Kebumen Jawa Tengah cukup tinggi, yaitu berkisar 300 pasien dalam satu bulan dengan kasus yang bervariasi. Dari total pasien yang ada 50\% diantaranya yaitu sekitar 150 pasien dilakukan tindakan anestesi dengan menggunakan jenis anestesi umum (general anestesi), baik dengan teknik intravena anestesi (TIVA), anestesi inhalasi dengan sungkup muka (face mask) maupun dengan menggunakan teknik intubasi, dari 150 pasien yang dilakukan general anestesi tersebut $30 \%$ nya 50 adalah pasien operasi pada anak-anak. Dari hasil studi pendahuluan kasus yang peneliti lakukan pada bulan Maret sampai April 2013, terdapat kasus kejadian $66 \%$ yaitu 33 anak yang waktu pemulihannya lebih dari 30 menit dengan tubuh yang gemuk IMT $>25$ dan operasi yang lama $>2$ jam, sedangkan pada pasien dengan berat badan normal (IMT 18,5-25) dan lama anestesi kurang dan dari 2 jam waktu pulih sadarnya cepat kurang dari 30 menit, penilaian menggunakan Steward score pada pasien anak yang menjalani operasi dengan general anestesi. Selama ini di Rumah Sakit Umum Daerah Kebumen Jawa Tengah perhitungan IMT dan pemantauan pulih sadar pasien anak belum diterapkan secara optimal.

Berdasarkan uraian tersebut peneliti tertarik untuk meneliti tentang "Hubungan indeks massa tubuh dan lama anestesi dengan waktu pulih sadar pada anak dengan general anestesi di Rumah Sakit Umum Daerah Kebumen Jawa Tengah".

\section{Metode}

Jenis penelitian ini merupakan penelitian observasional analitik dengan menggunakan metode kuantitatif yaitu untuk mencari hubungan indeks massa tubuh dan lama anestesi dengan waktu pulih sadar pada anak pasca general anestesi. Penelitian ini berusaha menemukan atau menjelaskan hubungan antara variabel-variabel dengan cara menggunakan metode perhitungan statistik.

Desain penelitian ini adalah survey cross sectional yaitu suatu penelitian untuk mempelajari dinamika korelasi dengan cara pendekatan, observasi, observasi partisipatif atau pengumpulan data sekaligus pada suatu saat (point time approach), artinya tiap subjek penelitian hanya diobservasi sekali saja dan pengukuran dilakukan terhadap status karakter atau variabel subjek pada saat pemeriksaan, namun hal ini tidak berarti bahwa semua subjek penelitian diamati pada waktu yang sama.

\section{Prosedur Penelitian}

Ruang lingkup dalam penelitian adalah keperawatan anestesi reanimasi. Sebagai subyek dalam penelitian ini adalah semua pasien anak yang akan menjalani operasi dan dilakukan pembiusan dengan general anestesi di Instalasi Bedah Sentral (IBS) Rumah Sakit Umum Daerah Kebumen Jawa Tengah dalam kurun waktu 2 bulan. Penentuan tindakan anestesi dilakukan oleh dokter spesialis anestesi dan sesuai dengan standar operasional prosedur yang telah ada di instalasi bedah sentral RSUD Kebumen Jawa Tengah, sedangkan lama tindakan anestesi menyesuaikan dengan pembedahan yang dilakukan. Peneliti tidak melakukan intervensi atau manipulasi terhadap responden, peneliti hanya melakukan observasi hubungan indeks massa tubuh dan lama anestesi dengan waktu pulih sadar pasien anak pasca general anestesi.

\section{Hasil \& Pembahasan}

Tabel 1 menunjukkan bahwa jumlah responden anak terbanyak adalah berjenis kelamin perempuan yaitu 24 orang $(54,5 \%)$ dari total 44 responden dan selebihnya berjenis kelamin laki- 
laki yaitu 20 orang $(45,5 \%)$. Umur anak terbanyak adalah 9 tahun $(25,0 \%)$ dari total 44 responden. Jenis operasi terbanyak operasi adalah Hernia 7 orang $(13,6 \%)$ dari total 44 responden.

Tabel 2 menunjukkan bahwa sebagian besar Responden kategori indeks massa tubuh adalah ideal 25 orang $(56,8 \%)$ dari total 44 responden. Adapun Sebagian besar kategori waktu anestesi pada pasien anak adalah cepat, kurang dari 1 jam yaitu 28 orang $(63,6 \%)$ dari total 44 responden, sedangkan 16 orang $(36,4 \%)$ waktu anestesinya lama yaitu lebih dari 1 jam.

Sebagian besar waktu pulih sadar pasien anak yang menjalani anestesi umum adalah cepat yaitu sadar kurang dari 30 menit setelah pengakhiran anestesi sebanyak 24 orang $(54,5 \%)$ dari total sample, sedangkan sisanya 20 orang $(45,5 \%)$ pasien anak yang menjalani anestesi umum pulih sadarnya lama yaitu lebih dari 30 menit.

Pada Tabel 3 dapat dilihat bahwa pasien dengan indeks massa tubuh ideal yang pulih sadar cepat sebelum 30 menit adalah sebanyak 18 orang (72\%) dan pulih sadar lama setelah 30 menit sebanyak 7 orang (28\%), sedangkan pasien dengan indeks massa tubuh gemuk yang pulih cepat sebelum 30 menit sebanyak 6 orang (31,58\%) dan pasien indeks massa tubuh tidak gemuk yang pulih setelah 30 menit sebanyak 13 orang $(68,42 \%)$. Kemudian pasien dengan waktu/ lama anestesi cepat kurang dari 1 jam yang pulih sadar cepat sebelum 30 menit adalah sebanyak 20 orang $(71,43 \%)$ dan pulih sadar lama setelah 30 menit sebanyak 8 orang $(28,57 \%)$, sedangkan pasien dengan waktu anestesi lama lebih dari 1 jam yang pulih sadar cepat sebelum 30 menit adalah sebanyak 4 orang (25\%) dan pulih sadar lama setelah 30 menit sebanyak 12 orang (75\%).

Tabel 4 menunjukkan bahwa terdapat hubungan antara indeks massa tubuh dengan waktu pulih sadar pasien pasca general anestesi, nilai Odds Ratio antara indek massa tubuh dengan waktu pulih
Tabel 1 | Distribusi frekuensi karakteristik responden berdasarkan jenis kelamin, umur, jenis operasi di instalasi bedah RSUD Kebumen

\section{Karakteristik Responden Jumlah Persentase}

(n)

\begin{tabular}{|c|c|c|c|}
\hline \multicolumn{4}{|l|}{ Jenis kelamin } \\
\hline & Laki-laki & 20 & 45,5 \\
\hline & Perempuan & 24 & 54,5 \\
\hline \multicolumn{4}{|l|}{ Umur } \\
\hline & 5 tahun & 8 & 18,2 \\
\hline & 6 tahun & 5 & 11,4 \\
\hline & 7 tahun & 8 & 18,2 \\
\hline & 8 tahun & 7 & 15,9 \\
\hline & 9 tahun & 11 & 25,0 \\
\hline & 10 tahun & 1 & 2,3 \\
\hline & 11 tahun & 4 & 9,1 \\
\hline \multicolumn{4}{|l|}{ Jenis Operasi } \\
\hline & Appendictomi & 3 & 6,8 \\
\hline & Debrident & 4 & 9,1 \\
\hline & Eksisi & 5 & 11,4 \\
\hline & FrClavicula & 1 & 2,3 \\
\hline & FrFemur & 1 & 2,3 \\
\hline & FrRadius & 2 & 4,5 \\
\hline & Heating & 6 & 15,9 \\
\hline & Hernia & 7 & 13,6 \\
\hline & Hidrokel & 5 & 11,4 \\
\hline & Ileus Obstruksi & 2 & 4,5 \\
\hline & Labioplasti & 1 & 2,3 \\
\hline & Laparatomi & 3 & 6,8 \\
\hline & Tonsilektomi & 4 & 9,1 \\
\hline
\end{tabular}

Tabel 2 | Distribusi frekuensi karakteristik responden berdasarkan indeks massa tubuh, lama anastesi dan waktu pulih sadar di Instalasi Bedah RSUD Kebumen

\begin{tabular}{|cccc}
\multicolumn{2}{c}{ Karakteristik Responden } & $\begin{array}{c}\text { Jumlah } \\
\text { (n) }\end{array}$ & $\begin{array}{c}\text { Persentase } \\
\text { (\%) }\end{array}$ \\
\hline Indeks Massa Tubuh & & & \\
& Ideal & 39 & 59.1 \\
\cline { 2 - 4 } Lama Anastesi & Gemuk & 27 & 40.9 \\
& Cepat & 28 & 42.4 \\
\hline \multirow{2}{*}{ Waktu Pulih Sadar } & Lama & 38 & 57.6 \\
& Cepat & 31 & 46.96 \\
& Lambat & 35 & 53.03 \\
\hline
\end{tabular}


Tabel 3 | Tabulasi silang antara Indeks Massa Tubuh dan Lama Anastesi dengan Waktu Pulih Sadar Pasien di Ruang Pulih Sadar Instalasi Bedah RSUD Kebumen

\begin{tabular}{|c|c|c|c|c|c|c|c|}
\hline \multirow{3}{*}{ Variabel } & & \multicolumn{4}{|c|}{ Waktu Pulih } & \multirow{3}{*}{$\begin{array}{c}\text { Total } \\
\Sigma\end{array}$} & \multirow{3}{*}{$\%$} \\
\hline & & \multicolumn{2}{|c|}{ Cepat } & \multicolumn{2}{|c|}{ Lambat } & & \\
\hline & & (n) & (\%) & (n) & $(\%)$ & & \\
\hline \multicolumn{8}{|l|}{ Indeks Massa Tubuh } \\
\hline & Ideal & 18 & 72 & 7 & 28 & 25 & 100 \\
\hline & Gemuk & 6 & 31,58 & 13 & 68,42 & 19 & 100 \\
\hline & $\Sigma$ & 24 & 54,54 & 20 & 45,46 & 44 & 100 \\
\hline \multicolumn{8}{|l|}{ Lama Anastesi } \\
\hline & Cepat & 20 & 71,43 & 8 & 28,57 & 28 & 100 \\
\hline & Lama & 4 & 25 & 12 & 75 & 16 & 100 \\
\hline & $\Sigma$ & 24 & 54,54 & 20 & 45,46 & 44 & 100 \\
\hline
\end{tabular}

Tabel 4 | Hasil Uji Chi Square tabulasi silang antara Indeks Massa Tubuh dan Lama Anastesi dengan Waktu Pulih Sadar Pasien di Ruang Pulih Sadar Instalasi Bedah RSUD Kebumen

\begin{tabular}{|c|c|c|c|c|c|}
\hline \multirow{2}{*}{ Variabel } & & \multicolumn{2}{|c|}{ Waktu Pulih } & \multirow{2}{*}{ OR } & \multirow{2}{*}{$\begin{array}{c}\text { Asymp.* } \\
\text { sig(2-sided) }\end{array}$} \\
\hline & & Cepat & Lambat & & \\
\hline \multicolumn{4}{|l|}{ Indeks Massa Tubuh } & \multirow{3}{*}{5,571} & \multirow{3}{*}{0,008} \\
\hline & Ideal & 18 & 7 & & \\
\hline & Gemuk & 6 & 13 & & \\
\hline \multicolumn{4}{|l|}{ Lama Anastesi } & \multirow{3}{*}{7,500} & \multirow{3}{*}{0,003} \\
\hline & Cepat & 20 & 8 & & \\
\hline & Lama & 4 & 12 & & \\
\hline
\end{tabular}

sadar adalah 5,571 dengan probabilitas asymp. sig (2-sided) 0,008. Dan juga terdapat hubungan antara lama anestesi dengan waktu pulih sadar pasien pasca general anestesi, nilai Odds Ratio antara lama anestesi dengan waktu pulih sadar adalah 7,500 dengan probabilitas asymp. sig (2sided) 0,003.

Sesuai dengan teori dan penelitian sebelumnya bahwa angka morbiditas serta mortalitas perioperatif lebih sering pada neonatus dan infant bila disbanding dengan kelompok yang lebih tua, dikarenakan oleh perbedaan karakteristik fisiologis yang mencolok bila dibandingkan dengan kelompok usia lain. ${ }^{2}$ Perbedaan fisiologis pada neonatus dan infant dibanding dengan kelompok usia yang lebih tua adalah sawar darah otak yang belum matang sehingga obat-obatan anesthesia terutama fentanil yang dapat menembus sawar darah otak dengan sangat mudah. ${ }^{8}$

Perbedaan lainnya adalah fungsi hati yang belum matang sehingga dapat menurunkan fungsi enzim hati dan biotransformasi obat-obatan anestesia. ${ }^{1}$ Selain itu, rasio luas permukaan tubuh yang lebih besar pada berat badan dengan sedikit lemak subkutan akan lebih mudah kehilangan panas dan mengalami hipotermia ${ }^{2}$ Kondisi hipotermia ini merupakan salah satu factor yang akan mempengaruhi waktu pulih sadar.

Terdapat hubungan antara Indeks Massa Tubuh dengan waktu pulih sadar pasien, hal ini sejalan dengan Connelly ${ }^{11}$. Pada pasien obesitas terjadi peningkatan konsumsi oksigen dan peningkatan produksi karbondioksida, akan tetapi basal metabolik rate tetap normal karena berhubungan dengan luasnya permukaan tubuh. Penurunan volume cadangan ekspirasi dan penurunan Fraction Residual Capasity (FRC) terjadi pada posisi pasin tegak lurus sehingga tidal volume normal tidak terpenuhi, efek ini diperparah bila pasien dalam posisi terlentang. Hasil dari ini adalah kelainan ventilasi dan perfusi, shunting dari kiri ke kanan, dan hipoksemia. Elastisitas dinding dada berkurang pada obesitas, walaupun elastisitas paru-paru tidak berubah. Fungsi pernapasan, 
seperti kapasitas vital paksa, volume ekspirasi paksa, dan arus ekspirasi puncak, tidak berubah dalam obesitas. Seiring dengan meningkatnya obesitas, sindrom hipoventilasi dapat terjadi. Ini dicirikan dengan hilangnya dorongan hiperkapnia, apnea tidur, hypersomnolence, dan kesulitan saluran udara. Ini dapat berkembang menjadi sindrom Pickwickian (hiperkarbia, hipoksia, polycytemia, hypersomnolence, hipertensi paru, dan kegagalan biventricular).

Pasien obesitas dengan sindrom obstruktif saluran napas atas dapat dikelompokkan menjadi tiga kategori yaitu orang-orang dengan OSA (Obstructive Sleep Apnoe), sindrom hypoapnea obstruktif, dan resistensi saluran udara bagian atas $^{3}$. Sampai dengan $50 \%$ dari pasien obesitas telah mengalami OSA secara signifikan. OSA didefinisikan sebagai 10 detik atau lebih dimana terjadi penghentian total aliran udara dalam waktu lima atau lebih perjam tidur meskipun terjadi upaya pernafasan terus-menerus terhadap glottis yang tertutup dalam kombinasi dengan penurunan oksigenasi arteri lebih besar dari $4 \%$. Indeks apneahypoapnea mengkuantifikasi tingkat keparahan OSA. Indeks di atas 30 berarti OSA, dan indeks 1630 berarti OSA moderat. Kelainan fisiologis akibat OSA termasuk hipoksemia, hypercapnia, vasoconstriction paru dan sistemik, dan polycytemia sekunder. Hasil dalam peningkatan risiko penyakit jantung dan penyakit pembuluh darah ischemic otak. Obesitas hipoventilasi (pickwickian) sindrom hasil dari sindrom jangka panjang dan terlihat pada $5 \%$ sampai $10 \%$ dari pasien tidak sehat obesitas. Hal itu adalah kombinasi dari hipoventilasi obesitas dan kronis mengakibatkan hipertensi paru dan pulmonalecor. ${ }^{6}$

Salah satu komplikasi utama pasca-anestesia pada pediatrik adalah keterlambatan pulih sadar. Penyebab keterlambatan pulih sadar pascaanestesia adalah efek residual dari obat anestetik, sedatif, analgesik, durasi anestesi, dan hipotermia. Hasil penelitian Defry dkk menunjukan angka kejadian keterlambatan pulih sadar pada pasien pediatric. Faktor yang mempengaruhi waktu pulih sadar salah satunya adalah durasi anestesia . Lama tindakan anestesi berpotensi memiliki pengaruh besar khususnya agent volatil dengan konsentrasi yang lebih tinggi dalam darah dan jaringan (khususnya lemak), kelarutan, durasi anestesi yang lebih lama, sehingga agen-agen ini harus berusaha mencapai keseimbangan dengan jaringan tersebut. ${ }^{4}$

Hipotesis ini sejalan dengan penelitian yang dilakukan $\mathrm{Kasim}^{7}$, hubungan indeks massa tubuh dengan waktu pulih sadar pasca general anestesi di instalasi bedah sentral RSUD wates, kabupaten Kulon Progo. Kesimpulan dari penelitian menyatakan terdapat hubungan indeks massa tubuh dengan wektu pulih sadar pasca general anestesi.

Hipotesis ini sejalan dengan penelitian yang dilakukan Kunto ${ }^{8}$ tentang hubungan lama tindakan anestesi dengan waktu pulih sadar pasien pasca general anestesi di instalasi bedah sentral RSUD magelang. Kesimpulan dari penelitian menyatakan terdapat hubungan lama tindakan anestesi dengan waktu pulih sadar pasca general anestesi.

\section{Kesimpulan}

Berdasarkan hasil penelitian dan pembahasan tentang hubungan Indeks Massa Tubuh dan lama anestesi dengan waktu pulih sadar pada anak pasca general anestesi di Rumah Sakit Umum Daerah Kebumen Jawa Tengah, dapat ditarik kesimpulan bahwa Indeks Massa Tubuh pada anak dengan general anestesi sebagian besar Ideal yaitu $56,8 \%$ dengan waktu pulih sadar sebagian besar cepat yaitu $54,5 \%$. Waktu anestesi pada anak dengan general anestesi di RSUD Kebumen Jawa Tengah sebagian besar cepat yaitu $63,6 \%$, dengan waktu pulih sadar sebagian besar Cepat yaitu 54,5\%. Berdasarkan hasil uji di dapatkan ada hubungan lama anestesi dengan waktu pulih sadar pada anak pasca general anestesi.

\section{Bibliografi}

1. Bharti N., Batra YK., Kaur H. 2009. Paediatric perioperative cardiac arrest and its mortality: database of a 60-month period from a tertiary care paediatric centre. Eur J Anaesthesiol. No. 26 vol 6, 490-5.

2. Butterworth JF, Mackey DC, Wasnick JD. 2013. Pediatric anesthesia. Dalam: Morgan GE, Mikhail M, penyunting. Clinical anaesthesiology. Edisi ke-5.; hlm. 877-905. Mc- Graw Hill, New York.

3. Daniel. 2008. Misteri Sleep Apnea Tidak Hanya 
Sekedar Dengkuran. http//:www.majalah-farmacia. com.diakses tgl 30 September 2018.

4. Defry Arya Dinata., Iwan Fuadi., Ike Sri Rezeki, 2014, Waktu Pulih Sadar pada Pasien Pediatrik yang Menjalani Anestesi Umum di RS Hasan Sadikin Bandung. Penelitian. FK Padjajaran.

5. Handani. 2010. Hubungan Status Fisik Pra General Anestesi dengan Waktu Pulih Pasien di ruangan Pulih Sadar Instalasi Bedah RSUD Sungai Liat Bangka.

6. Iswanto, 2008. Gangguan Bernafas Saat Tidur, Hubungan Mendengkur dengan Stroke,Yogyakarta, RS Bethesda, Yogyakarta.

7. Kasim, 2012. Hubungan Indeks Massa Tubuh dengan Waktu Pulih Sadar Pasca General Anestesi di Instalasi Bedah Sentral RSUD Wates, Kabupaten Kulon Progo.

8. Kunto, 2012. Hubungan Lama Tindakan Anestesi dengan Waktu Pulih Sadar Pasien Pasca General anestesi di Instalasi Bedah Sentral RSUD Magelang.

9. Sinclair R, Faleiro R. 2006. Delayed recovery of conciousness after anaesthesia: contin Educ Anaesth Crit Care Pain:;6(3): 114-8.

10. Susetyowati, 2010. Metodologi Penelitian dan IImu Statistic, EGC, Jakarta.

11. Mangku, G. 2010, Buku Ajar Anestesi dan Reanimasi, vol 1, PT Indeks Permata Puri Meida, Jakarta.

12. Morgan, E. Mikhail, M.S. Murray, M.J. 2006. Clinical Anesthesiology 4 th edition. Lange Medical Books,USA.

13. Said A., Kartini A. Suryadi, M. Ruswan Dahlan. 2002. Petunjuk Praktis : Anestesiologi. Edisi Kedua, Bagian Anestesiologi Dan Terapi Intensif, Jakarta FKUI.

14. Smeltzer \& Bare. 2002. Clinical Anesthesiology (4th ed). McGraw-Hill Companies, USA.

15. Connelly TM., Juza RM., Sangster W., Sehgal R., Tappouni RF., Messaris E. 2014. Volumetric fat ratio and not body mass index is predictive of ileocolectomy outcomes in Crohn's disease patients . Dig Surg ;vol $31: 219-224$ 